\title{
Study of borehole stability of Marcellus shale wells in longwall mining areas
}

\author{
Yi Wang $\cdot$ Robert Watson · Jamal Rostami • \\ John Yilin Wang • Mark Limbruner • \\ Zhong He
}

Received: 27 May 2013/ Accepted: 6 September 2013/Published online: 26 September 2013

(c) The Author(s) 2013. This article is published with open access at Springerlink.com

\begin{abstract}
With the widespread drilling of gas wells in Marcellus shale, there are high potentials for wellbore instability problems when wells are located in longwall mining areas, which in many areas such as southwest Pennsylvania, West Virginia, and eastern Ohio are being used for extraction of the coal seam overlaying the gas reserves. The ground deformation, caused by coal mining, could generate large horizontal displacement and complex stress change in subsurface rock. This in turn triggers ground movement which can cause casing failure, and thus interruption in the operation of the well that raises safety and environmental concerns. This could result in shutting down the well for repair, or permanent abandonment. Thus, it is critical to characterize the parameters related to the longwall mining process and to propose a general casing design guideline in such areas. In this paper, numerical modeling was utilized to simulate the complex ground conditions and resulting stresses and strains in longwall mining areas. A casing design spreadsheet was then constructed for design of appropriate selection of casings, based on the results of the numerical modeling. Our results were validated with field practices of wellbore design in southwest Pennsylvania. This paper also provides a methodology for investigating potential ground deformations, resulting stress/strain changes, and wellbore stability issues for oil and gas
\end{abstract}

Y. Wang $\cdot$ R. Watson $\cdot$ J. Rostami $\cdot$ J. Y. Wang $(\bowtie)$ Energy and Mineral Engineering Department, The Pennsylvania State University, 110 Hosler Building, University Park, PA 16802, USA

e-mail: john.wang@psu.edu

M. Limbruner $\cdot$ Z. He

Range Resources Appalachia L.L.C, Canonsburg, PA, USA wells drilled in longwall mining areas in Marcellus shale or similar formations worldwide with active coal mining activities.

Keywords Hydraulic fracture propagation modeling . Tight gas reservoirs

\section{List of symbols}

$c^{\prime} \quad$ Cohesion of the rock, dimensionless

$d_{n} \quad$ Outside diameter of casing, $\mathrm{ft}$

$F_{a} \quad$ Pipe body strength, psi

$F_{\mathrm{ab}} \quad$ Axial force caused by the effect of bending, lbf

$F_{j} \quad$ Joint strength, lbf

$H \quad$ Depth of measured point, $\mathrm{ft}$

$K_{0} \quad$ Ratio of horizontal stress and vertical stress, fraction

$N_{a} \quad$ Safety factor for pipe body, dimensionless

$N_{c} \quad$ Safety factor for collapse, dimensionless

$N_{i} \quad$ Safety factor for burst, dimensionless

$N_{j} \quad$ Safety factor for joints, dimensionless

$P_{c} \quad$ Maximum external pressure along the casing, psi

$P_{\text {cc }} \quad$ Collapse strength, psi

$p_{i} \quad$ Injection pressure, $\mathrm{psi}$

$P_{i} \quad$ Internal yield pressure, $\mathrm{psi}$

$P_{\text {in }} \quad$ Casing internal pressure, psi

$w \quad$ Pipe body weight per foot, $\mathrm{lbf} / \mathrm{ft}$

$W \quad$ Pipe body weight, lbf

$\alpha \quad$ Dogleg-severity angle, deg/100 ft

$\rho_{g} \quad$ Methane density, $\mathrm{lbm} / \mathrm{ft}^{3}$

$\rho_{m} \quad$ Mud density, $1 \mathrm{bm} / \mathrm{ft}^{3}$

$\sigma_{H} \quad$ Horizontal stress along the well trajectory, psi

$\sigma_{n}^{\prime} \quad$ Normal effective stress on the slip plane, psi

$\sigma_{V} \quad$ Vertical stress along the well trajectory, psi

$\varphi^{\prime} \quad$ Internal friction angle, deg

$\tau_{\max } \quad$ Maximum shear stress, psi

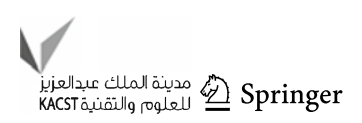




\section{Introduction}

In the oil and gas industry, wellbore stability is considered to be a critical issue during well drilling and its subsequent completion. Lack of wellbore stability has led to many instances of casing failure and significant economic losses as well as safety and environmental issues. As such, research on the factors that can prevent casing failure is necessary. Factors and forces that need to be studied are those that are applied to the casing and the resulting stress and strains or displacements which could lead to an unstable wellbore.

The issue of wellbore stability is a significant problem for wells located in active mining areas. In particular, wells in mining areas where the longwall mining technique is used for the extraction of coal could be subject of wellbore casing failures caused by substantial ground movement due to removal of the large panels. With the development of unconventional reservoirs such as the Marcellus shale in active mining areas of western PA and in general coal reserves in Appalachia that overlays the Marcellus shale, the possibility of wellbore failure due to mining activities needs to be examined. Given the geometric setting of the longwall panels and the remaining pillars, factors that are related to longwall mining such as induced stresses and resulting strains and displacements in the ground around the mined out area (gob), pillars of certain size, as well as surface subsidence should be taken into consideration. The stresses, strains and deformations are a function of characteristics of the mining area and panel geometry, geological properties of the formations above and below the workable coal seam, and the wellbore design and completion method used for the drilling of the gas wells tapping into Marcellus shale. This study will focus on the geological settings, geometry of the longwall panel and pillars, and resulting stresses strain and deformation caused by mining activities. The main focus of the study is the stability of the wellbores that are designed to go through large size barrier pillars. A separate study can look into the possibility of the drilling and wellbore completion in the gob, which is the caved area above the mined panel.

The main objective of this research is to develop a general model for estimation of the stresses, strain, and ground movement, which can then be used to describe the worst case conditions that may occur near the wellbore in longwall mining areas. With this input, a wellbore can be designed and completed to withstand the anticipated loads. This study allows evaluating the suggested wellbore completion design to mitigate potential problems that could be caused by excessive ground movement and result in wellbore failures. The suggested design will be compared to what is used in practice by gas well drilling companies to examine their adequacy to assure wellbore stability. The result of this study will facilitate development of the unconventional gas resources in these areas which covers rather sizable land plots in Western PA, WV, OH, and MD.

\section{Casing failure mechanism}

Ground deformation and associated bedding plane slip and overburden shear can damage the gas wells. Usually, casing failure arises through shear owing to displacement of the rock strata along bedding planes or along steeply inclined fault planes. There are certain indicators pointing toward reservoirs which are most likely to suffer casing damage due to reservoir compaction. Following is a brief list of potential failure mechanisms.

\section{Local buckling}

Local buckling is buckling along the casing wall while the center line of the casing stays straight. This contrasts with column buckling where the center line of the casing bends. It occurs at very short lengths, when the casing is sufficiently well supported to prevent column buckling. Also, it is more likely to occur in the casing body near the connection. However, if there is a lack of support, critical column buckling would occur and dominate the casing damage prior to any significant local buckling. So, local buckling is believed to be not a problem for working through the casing. This is especially true if certain provisions are considered in the wellbore completion such as protection casing as will be discussed later in this paper.

\section{Crushing}

Crushing of the casing cross section is a serious damage mechanism secondary in importance to column buckling. It is stable and is caused by non-uniform mechanical loading between the sand, cement, and casing. Crushing damage can become significant and obstruct working through the casing after large depletion. When the sand is very compact or slightly compact, but depletion is very high, concerns for crushing become important and could dominate the choice of the casing size in the pay zone.

\section{Connection failure}

For the straight part of the well, the ground compaction would cause large, plastic, and compressive strain in the casing connections in the pay zone. Once the reservoir compacts, the displacement at the top of the reservoir can cause significant tensile strain along the casing above the pay zone. If the connection between casings is not as strong 
Fig. 1 Body of the elastic ground model in Phase $^{2}$

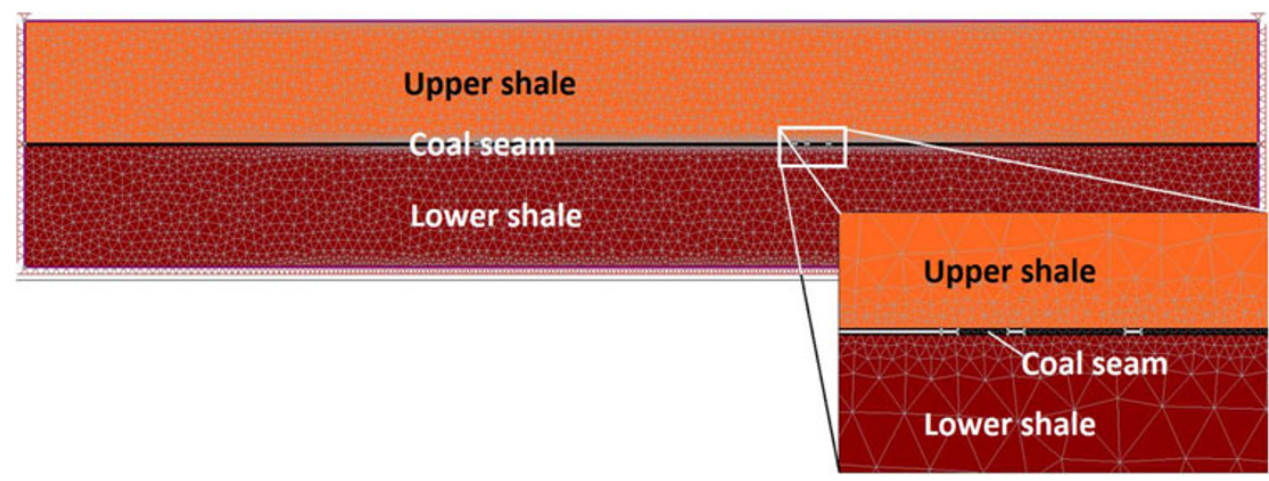

as the casing body, joint failure can occur in compression in the pay zone. In a reservoir, compressive strain will quickly yield the casing and joints, while the tensile strain in the overburden generally will stay elastic, but can exceed the joint strength if the connection is weak in tension. A huge axial load from casing body can also cause the joint failure. So, the joints need to be as good as the casing body in both tension and compression within the pay zone and for a few hundred feet above the pay zone. It is always good to meet this criterion during the casing design to avoid unnecessary risks for the well.

\section{Shear failure}

Usually, casing failure arises through shear owing to displacement of the rock strata along bedding planes or along steeply inclined fault planes. In this study, the most critical form of casing damage results from localized horizontal shear stress-induced displacements at weak lithology interfaces within the overburden during compaction or heaving caused by mining of a panel as the ground adjusts to the new conditions and such movements are marked by surface subsidence. This is more or less unique to situation in the longwall mining areas, and the maximum displacement and deformation are often related to weak lithology. This refers to the compaction-induced shear stresses in the general vicinity of the longwall panel, but the location of damage is generally determined by the position of weak lithological layers within the overburden. Though the induced shear stresses tend to distribute over relatively large depth intervals, the damage is generally localized. This damage does not exclusively occur at the flanks of the subsidence bowl, but is generally observed to be distributed over the field and gets magnified by local structural features in the ground. Other types of shear are associated with the production intervals of the well. For example, reservoir compaction shearing can lead to casing shear. The larger the horizontal shear stress and related strain in the zone, the greater is the casing failure potential in the overburden.

\section{Finite element analysis (FEA) model}

As noted above, the changes in ground stresses due to longwall mining is very complex and while the subsidence is observed and measured at the surface, the components of strain and deformation within the ground need to be determined to develop a proper well completion design. For this purpose, analytical solutions are often insufficient and numerical modeling seems to be the best option for determination of ground reaction to mining activities.

The modeling of the ground was performed by using finite element program Phase $^{2}$ by Rocscience $\odot$, a commercial program. In this study, a single horizontal coal seam located at a depth of $200 \mathrm{~m}(656 \mathrm{ft})$, with a thickness of $2 \mathrm{~m}(6.5 \mathrm{ft})$ was modeled. Figure 1 shows that there are three general different geological units: the upper layer (overburden), coal seam, and the lower layer. Table 1 displays the materials defined as elastic-plastic solid and the related properties. In Fig. 1, we can also see that there are two pillars of $15 \mathrm{~m}(49 \mathrm{ft})$ and $30 \mathrm{~m}(98 \mathrm{ft})$ in width on each side of the panel, and three gate roads of $5 \mathrm{~m}(16 \mathrm{ft})$ in width that comprise the access to the panels on each side. The model also includes a section of $198 \mathrm{~m}(649 \mathrm{ft})$ below

Table 1 Rock properties and elastic parameters used in numerical modeling

\begin{tabular}{|c|c|c|c|c|c|c|}
\hline Layers & $\begin{array}{l}\text { Young's modulus } \\
\text { (Mpa/Psi) }\end{array}$ & Poisson ratio & $\begin{array}{l}\text { Unit weight } \\
\text { (MN/m3/lb/in3) }\end{array}$ & Failure criterion & $\begin{array}{l}\text { Cohesion } \\
(\mathrm{MPa})\end{array}$ & $\begin{array}{l}\text { Friction angle } \\
\left({ }^{\circ}\right)\end{array}$ \\
\hline Upper layer & $4800 / 6.9 \mathrm{e}+05$ & 0.2 & $0.022 / 0.08$ & Mohr-Coulomb & 1 & 30 \\
\hline Coal seam & $3500 / 5.0 \mathrm{e}+05$ & 0.3 & $0.02 / 0.073$ & Generalized Hoek-Brown & & \\
\hline Lower layer & $4500 / 6.5 \mathrm{e}+05$ & 0.25 & $0.024 / 0.088$ & Mohr-Coulomb & 1 & 30 \\
\hline
\end{tabular}


the coal seam to allow for monitoring the stresses below the coal seam. The width of the longwall panel was assumed to be nearly $500 \mathrm{~m}(1,640 \mathrm{ft})$, which is the size of super panels that are being considered for longwall mining in the near future. In this model, an element length of $3 \mathrm{~m}$ was used as the mesh size, resulting in 12,842 elements in total for constructing the model of a longwall panel and adjacent entries and pillars. The upper boundary is stress free, and the lateral boundaries are the basal boundaries. Four stages are considered in this model, representing the ground in virgin conditions, after mining the tailgate entries, after completion of headgates, and after mining the longwall panel.

Calibration of the model using empirical formulas for estimation of the ground subsidence

Two empirical methods of subsidence prediction (Peng 2008; Gutierrez 2010) were used for estimating the ground subsidence. The results of numerical modeling were calibrated by changing different elastic properties and parameters of rock within a reasonable range to match the predicted subsidence using the empirical models. The estimated surface subsidence profiles by the empirical and numerical models were compared to find the material properties that could result in the best match between the estimated subsidence profiles. Once the material properties were selected based on the calibration of the numerical model with the empirical subsidence model, the calculated values of stresses, strain, and deformation along the vertical well trajectory passing through a barrier pillar (located at left-hand side of the extracted panel) was used to represent the worst case scenario for ground conditions along the wellbore. This was done by using a query function within the Phase ${ }^{2}$ program. Through this query line, the profiles of stresses and strains at certain points in the model could be obtained. When a reasonable match between the numerical result and the empirical formulas was obtained, the finite element modeling could predict the state of stresses and strain within the rock that could be used for evaluation of wellbore stability.

\section{Modeling results}

The comparison between numerical and empirical result for ground subsidence is shown in Fig. 2. One can see that the subsidence trough predicted by the numerical model is wider than the one calculated by the empirical formulas. This is possibly because of the nature of the FEA modeling, which is based on continuum and unable to perfectly simulate subsidence in this area, since it does not consider the possible discontinuities in the rock formation. After the coal is mined out, the position of the roof strata part of the overburden above the target panel seems to move below the coal seam, which is physically impossible. Thus the FEA model seems to overestimate the vertical and horizontal subsidence, as well as shear stress and strains around the upper strata. Even though these issues need to be resolved, the modeling results could be useful for analysis of the stress and strain in overburden layers in this project. The mismatch of the subsidence trough could very well be due to the assumption of elasticity and continuity of the ground over the panel and near surface, while in reality the ground is broken and the subsidence trough is smaller and slopes of the subsidence bowl are indeed sharper. This means that the reach of the subsidence area is smaller and
Fig. 2 Comparison of the subsidence profiles for a panel width of $500 \mathrm{~m}$ generated by numerical and empirical models

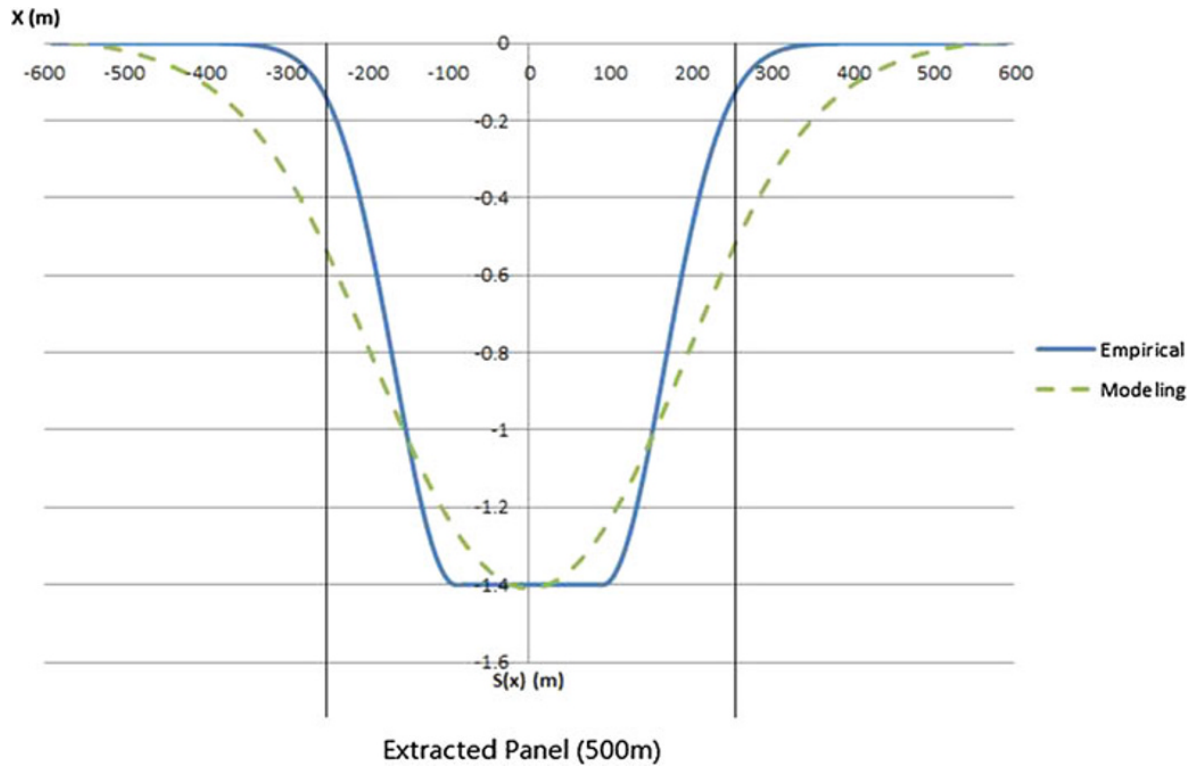


so are the horizontal stresses (shear and tensile) and similarly the strains and the horizontal displacement are anticipated to be lower than predicted by the FEA program.

\section{Horizontal displacement}

The horizontal displacement reaches a maximum at the inflexion point of the subsidence trough, where the curvature changes from convex to concave and the slope is also at its maximum. A traditional approach to estimate horizontal displacements is by linear correlation of the displacement profile to slope of the subsidence trough at the surface. According to Fig. 3, the maximum horizontal displacement could reach a maximum value of $15 \mathrm{in}$. along the well trajectory. This could be a little excessive and is possibly caused by the FEA modeling's overestimation, as stated above. In fact, this large displacement has been measured in some cases in Australia where a peculiar surface topography exists. Also, a huge horizontal displacement of $18 \mathrm{in}$. was measured in a Cumberland mine panel in Pennsylvania (Gutierrez 2010), which is not an exemplary common case. Therefore, we can conclude that the horizontal displacement measured in FEA modeling is slightly higher than that anticipated in the majority of cases. However, to conduct generic recommendations for the casings, the maximum horizontal shear strain was limited to $100 \mathrm{~mm}$ per $10 \mathrm{ft}$ pipe ( 4 inches per $30 \mathrm{ft}$ ) section, which is also based on the data from a finite difference modeling performed by commercial program FLAC (by ITASCA inc) (Rostami et al. 2012). This result is more realistic because it is closer to the majority of actual field observations, so the maximum shear strain of

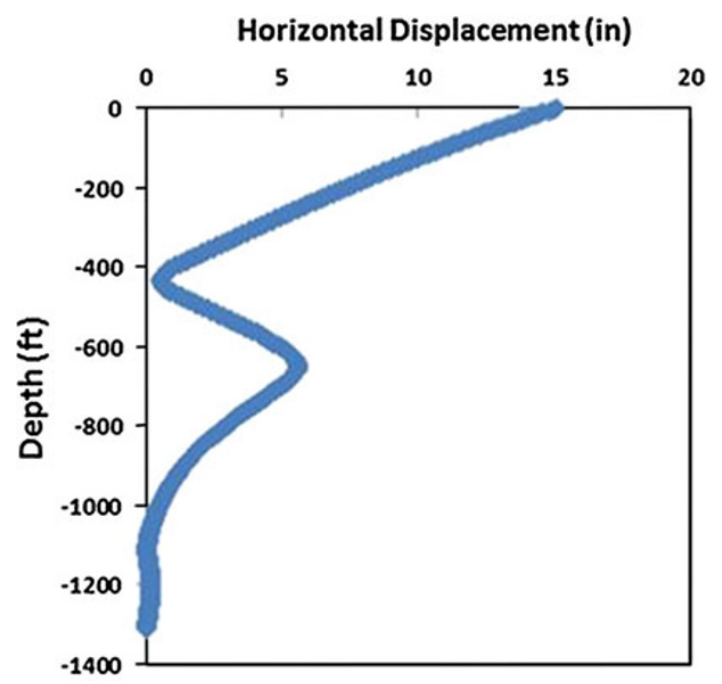

Fig. 3 Plot of horizontal displacement versus depth of gas well estimated by FEA modeling
$10^{-2}$ or $10 \mathrm{~cm}$ per $10 \mathrm{~m}$ of pipe was used in the following casing design process.

\section{Horizontal stress}

For FEA modeling, the horizontal stress in virgin ground is difficult to estimate, compared to vertical stress. This is due to the unknown nature of the horizontal stresses that could be dominated by tectonic stresses. In general, the ratio of horizontal to vertical stress in virgin ground is used to obtain the horizontal stress from estimated vertical stress which follows the gravitational stress field and is proven to be very close to reality:

$\sigma_{H}=\sigma_{V} K_{0}$

where $\sigma_{H}$ is the horizontal stress along the well trajectory and $K_{0}$ is the ratio of horizontal stress and vertical stress(normally $0.7 \sim 0.8$ in PA).

Therefore, the distribution of horizontal stress from the ground surface to a depth of $1,400 \mathrm{ft}$ could be similar to the vertical stress distribution, granted that coefficient of horizontal stresses are known through in situ stress measurements on site or through local trends. However after mining, the virgin stresses are redistributed and a new stress distribution is in effect, which in this case will include components of horizontal stresses. Since the well is located at one of the subsidence troughs of the panel, it would suffer from high horizontal stress along with the related horizontal displacement (Figs. 3, 4, 5, 6, 7, 8, 9, 10, $11,12)$ in the overburden strata. Below the coal seam, ground stresses will gradually get closer to the virgin stresses. In this area, high compressive vertical and horizontal stresses are anticipated due to transfer of load of the overburden from the gob area to the pillars.

Figure 4 shows the horizontal stresses ( $x$-direction) in virgin ground and the induced stresses that could reach $5.86 \mathrm{MPa}(850 \mathrm{psi})$, caused by mining of the coal in the longwall panel. The horizontal stresses reach a maximum value of $12.73 \mathrm{MPa}(1,846 \mathrm{psi})$ at the coal seam level and decreases to a depth of $274 \mathrm{~m}$ (900 ft). The stresses will then increase with depth as anticipated in virgin ground, since the effect of mining does not extend far below the coal seam. Examination of the estimated stresses and strains along the projected well location allows for quantifying the values needed for casing design.

\section{Shear stress}

Figure 5 shows that the shear stress estimated by the numerical modeling which starts from a small value around surface and increases to a maximum of $2.47 \mathrm{MPa}(358 \mathrm{psi})$ and $4.72 \mathrm{MPa}(685 \mathrm{psi})$ at a depth of about $130 \mathrm{~m}(380 \mathrm{ft})$ and immediately below the coal seam, respectively. These values 


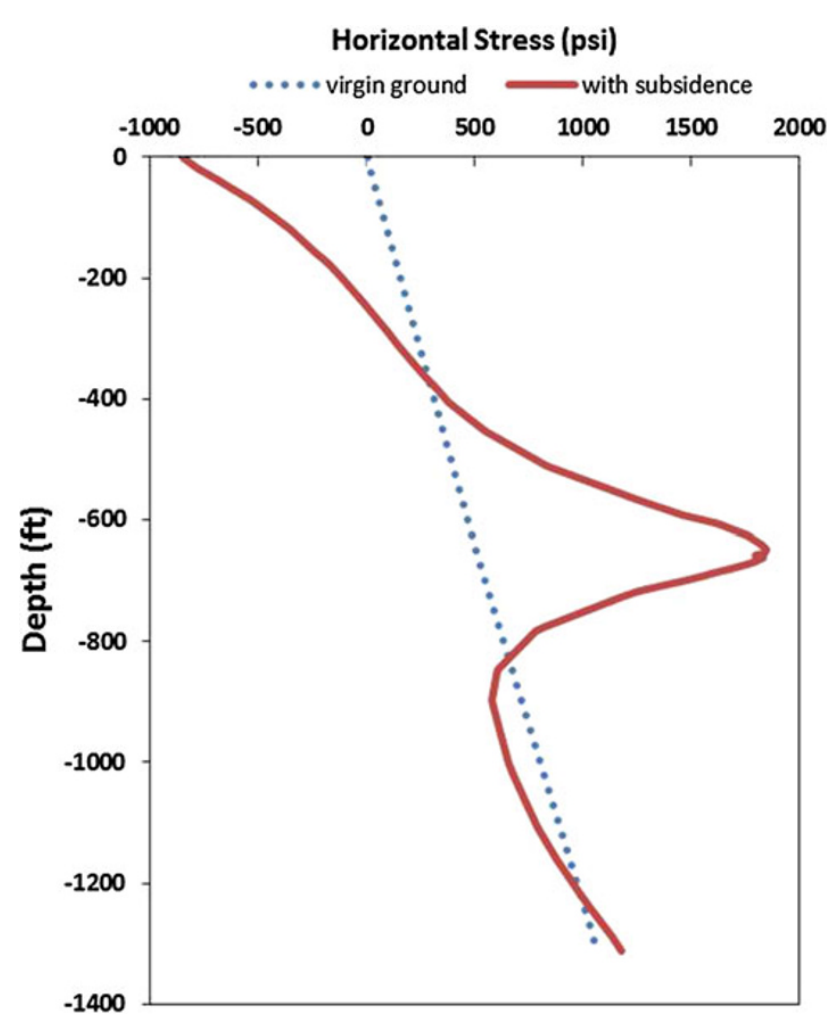

Fig. 4 Plot of horizontal stress versus depth of gas well estimated by numerical modeling

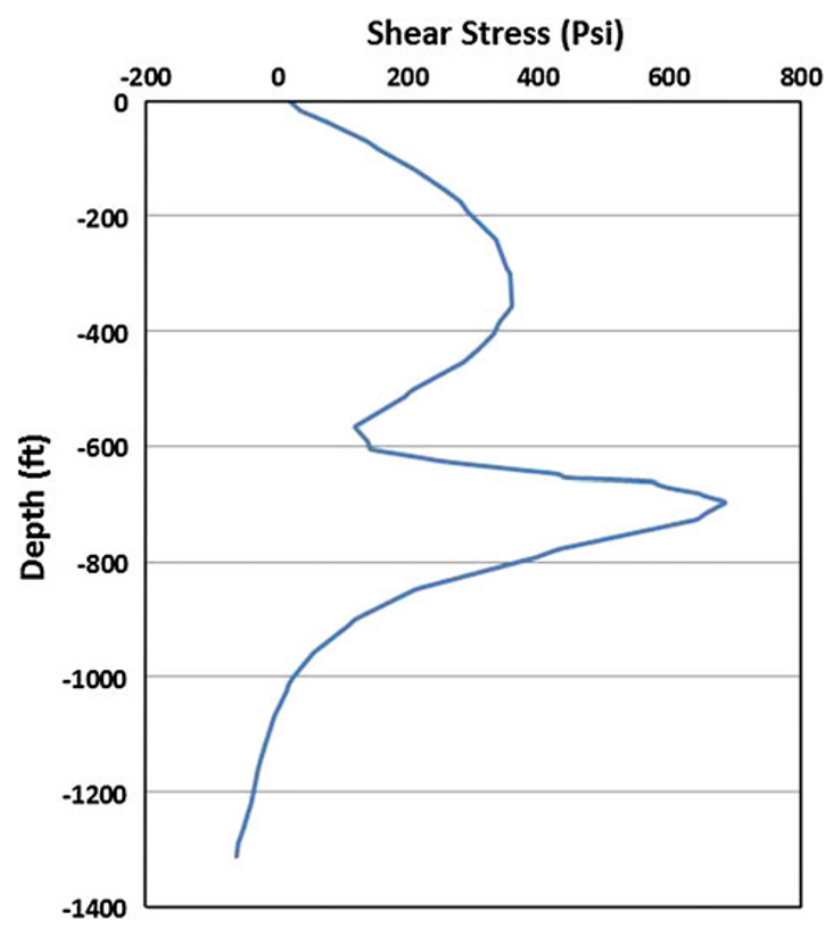

Fig. 5 Plot of shear stress versus depth of gas well based on numerical modeling can be taken into consideration in well design. Basically, the shear stress in this case is smaller than horizontal stress. For virgin ground, there will be nearly no shear stress along the well trajectory, because no deformation and stress change are present in this situation.

As noted before, the estimated subsidence profile by modeling did not match the empirical subsidence calculations. Therefore, the estimated strain was limited to the results obtained from the finite difference model, which showed better fit to the empirical model. To justify the accuracy of the numerical modeling in this research, field measurements within the wellbores in the longwall mining areas are strongly recommended.

\section{Casing design}

To alleviate or even avoid casing failure issues, proper casings should be selected to be used for well completion. Use of correct size, type, and number of casing in the well construction is halfway to success of the design. In a whole design, the integrated casing, cementing, mud, and blowout prevention control program should be taken into consideration. There are generally four types of casings used in completion: conductor pipe, surface casing, intermediate casing, and production casing. In this research, we need to utilize the four types of casing for the design and to add an intermediate casing serving as a coal protection casing.

To determine all types of casing's sizes applied in a well, one needs to start from the smallest casing string to be run in a hole. Once the smallest casing is fixed, other series of casing size and hole sizes can be determined. The smallest casing size is selected based on well testing and logging tools and production tools to be run in the well. In our case, the production casing, which is the smallest casing, is $51 / 2$ in. Figure 6 shows a typical tubing and bit selection chart. The bit sizes and other casing sizes can be selected according to this chart. After selecting the smaller casing sizes, proper bit and a larger casing string for the following run can be selected.

For casing design process, there are three types of loads that the designer needs to consider: collapse, burst, and tension. Collapse and burst loading are often the dominating stresses at a depth closer to the bottom hole, so at this point in the well the casings should be selected according to collapse and burst resistance. With a decreasing depth, the effect of collapse also decreases while burst and tension stresses become more critical. As a consequence, the criteria for design of the casing at the middle portion of the well are tension and burst stresses. As for the casing near the surface, tension stresses would be the most important factor that should be considered (Bourgoyne et al. 1986). 
Fig. 6 Casing/bit selection chart (Schlumberger)

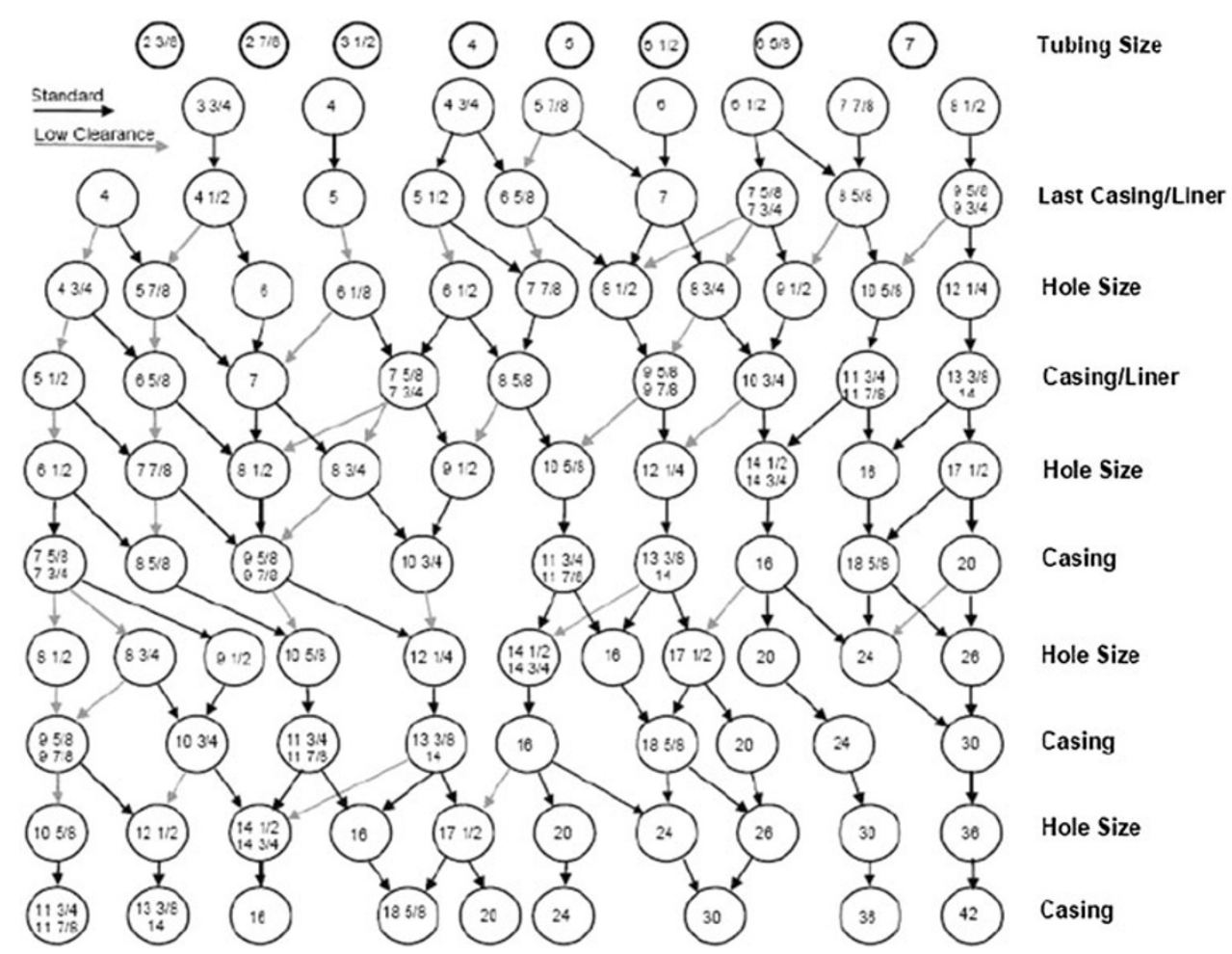

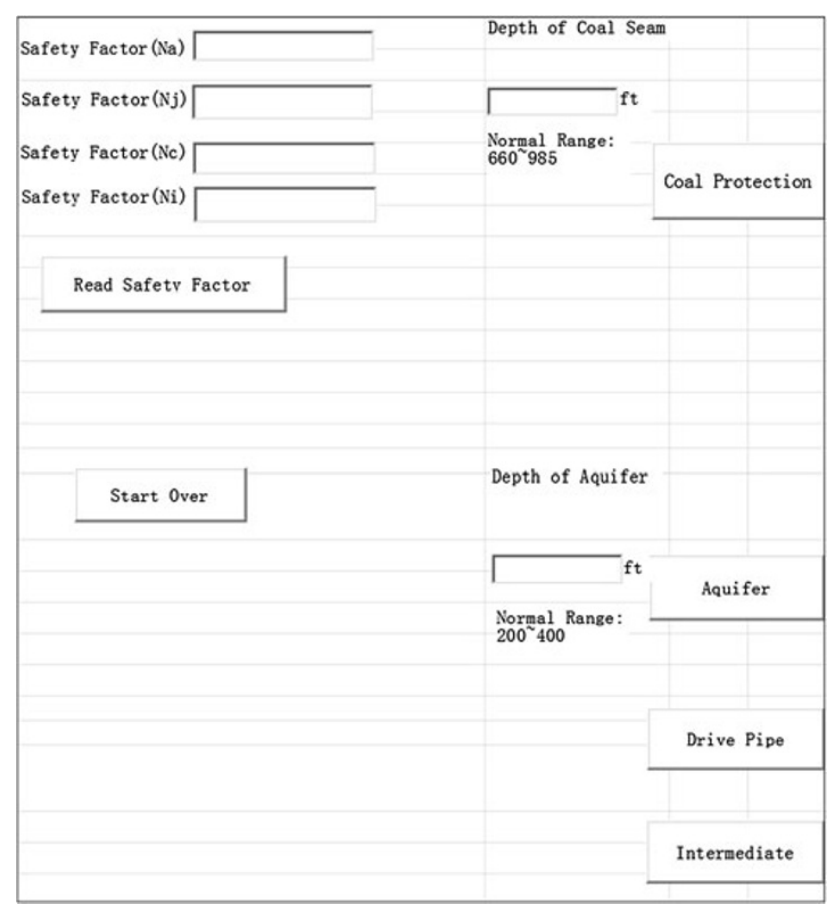

Fig. 7 The interface of inputs in the casing design model

\section{Casing design model description}

In this section, a casing design model is introduced to design casing strings for a gas well in the longwall mining area for production from the Marcellus shale. The stress/ strain data are obtained using numerical modeling of ground. The data used in the completion design are obtained by using a query function, which lists the calculated parameters along a vertical line representing the gas well. The stress/strain data obtained from modeling are used in the background spreadsheet for casing design and are not accessible by users. Also, the horizontal displacement observed from the FEA model needs to be considered in the casing design modeling. For mining geometries other than the one set forth, background stress and strain data need to be added to the spreadsheet prior to undertaking casing design. There are five types of casing to be used in gas well completion in the longwall mining areas. This system was included in the base casing/completion design model. The casings include: drive pipe, aquifer casing, coal protection casing, intermediate casing, and production casing. The model is built into a spreadsheet and allows an interactive design by changing the input parameters and shows the resulting casing and well completion design parameters. Figure 7 displays the interface of inputs in this model. In the case considered in this study, the coal seam depth is fixed to $200 \mathrm{~m}(660-670 \mathrm{ft})$. The depth of groundwater can be varied to between 60 and $120 \mathrm{~m}$ (200-400 ft). Through the input interface in this model, users are also allowed to input safety factors, which are used to quantify the minimum strength of all casings. Then by selecting the "read safety factors" and corresponding 
Fig. 8 A 2D schematic view of the casing size and bit size design results

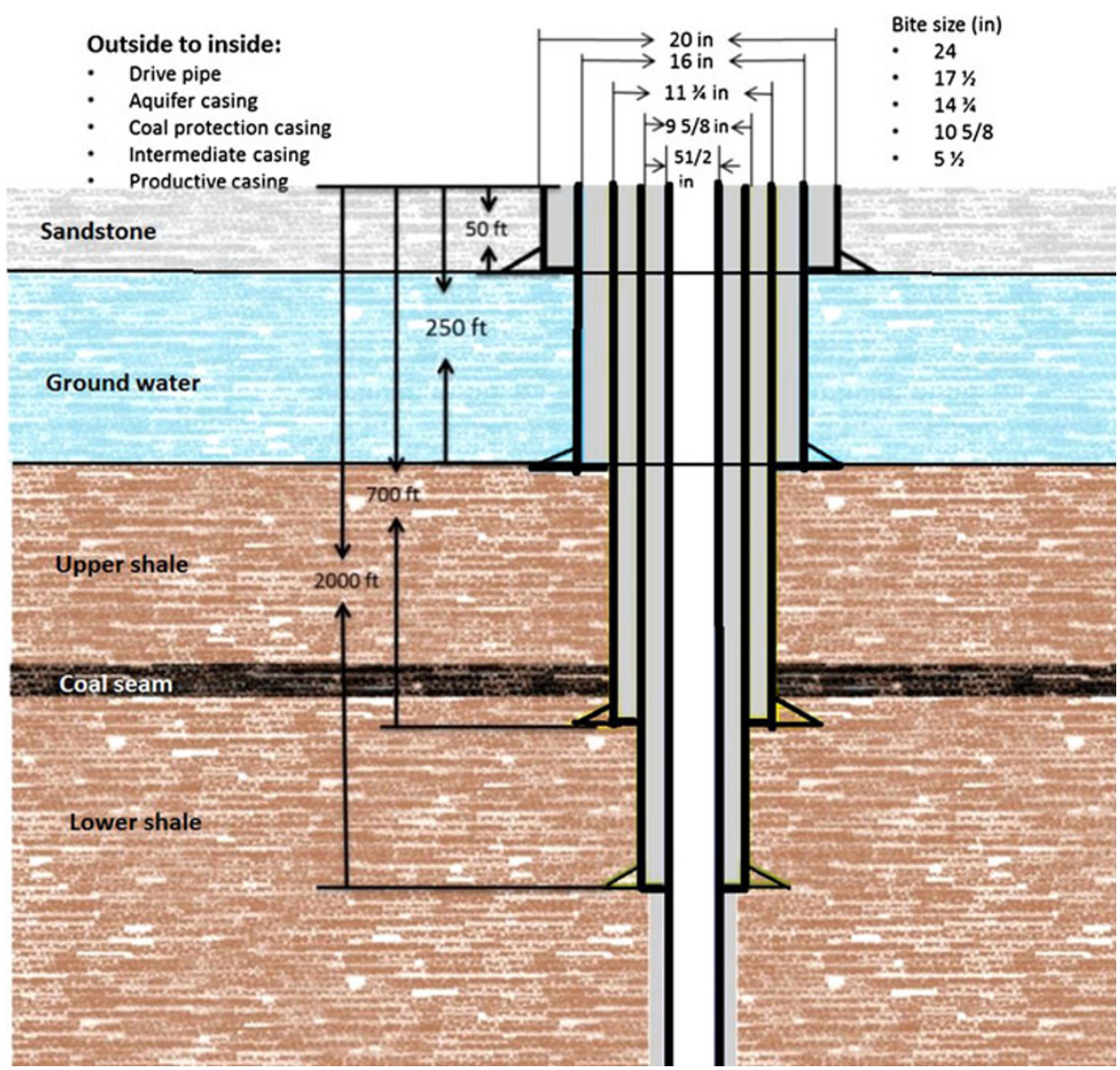

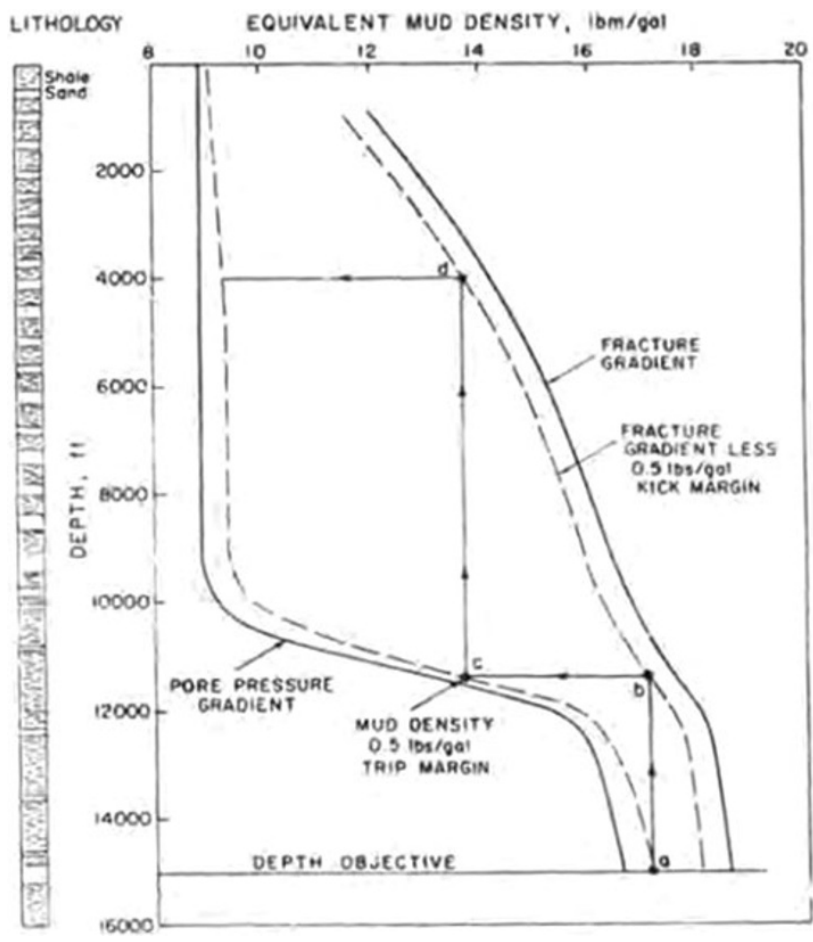

Fig. 9 Pore-pressure gradient and fraction gradient data (Bourgoyne et al. 1986) buttons, the user can see the results for various casing sizes. Users are able to click the "start over" button to erase all input data and calculated results, and retype other groups of data as needed. For the selection of casing, four tables of casings with various minimum performance properties were put at the right side of the buttons with the name of casings. After the initial setting and data entry, the model automatically selects proper casing size and grade for the aquifer casing, coal protection casing, intermediate casing, and drive pipe. Then, the numbers of available casings will appear in the "Results" column on the left side of the input data for manual selection of feasible casings for the given geometric and ground conditions. As noted before, if the geometry of the longwall panels, including the depth, width of the panel and size of the pillars change, numerical modeling has to be performed to revise the background data on stresses and strain that should be used in the wellbore completion design program.

\section{Selection of casing diameter and bit size}

First item in the design steps is to determine the outside diameter of production casing. This parameter is fixed to 5.5 in. which is commonly used in Marcellus shale gas 


\begin{tabular}{|c|c|}
\hline Term & Value \\
\hline \multicolumn{2}{|l|}{ Maximum stresses applied on casings } \\
\hline Max stress for drive pipe (Psi) & 850.3496 \\
\hline Max stress for aquifer casing (Psi) & 850.3496 \\
\hline Max stress for coal protection casing (Psi) & 1846.14 \\
\hline Max stress for intermediate casing (Psi) & 2410.8077 \\
\hline \multicolumn{2}{|l|}{ Production casing } \\
\hline OD of production casing (inch) & 5.5 \\
\hline OD of coupling for production casing (inch) & 6.05 \\
\hline Length of production casing $(\mathrm{ft})$ & 3000 \\
\hline \multicolumn{2}{|l|}{ Intermediate casing } \\
\hline OD of intermediate casing (inch) & 9.625 \\
\hline$O D$ of coupling for coal intermediate casing (inch) & 10.625 \\
\hline ID of intermediate casing (inch) & 8.679 \\
\hline Length of intermediate casing $(\mathrm{ft})$ & 2000 \\
\hline \multicolumn{2}{|l|}{ Coal protection casing } \\
\hline OD of coal protection casing (inch) & 11.75 \\
\hline OD of coupling for coal protection casing (inch) & 12.75 \\
\hline ID of coal protection casing (inch) & 10.772 \\
\hline Length of coal protection casing $(\mathrm{ft})$ & 700 \\
\hline \multicolumn{2}{|l|}{ Aquifer casing } \\
\hline OD of aquifer casing (inch) & 16 \\
\hline OD of coupling for aquifer casing (inch) & 17 \\
\hline ID of aquifer casing (inch) & 15.01 \\
\hline Length of aquifer casing $(\mathrm{ft})\left(250^{\sim} 450\right)$ & 250 \\
\hline \multicolumn{2}{|l|}{ Drive pipe } \\
\hline OD of drive pipe (inch) & 20 \\
\hline OD of coupling for drive pipe (inch) & 21 \\
\hline ID of drive pipe (inch) & 19 \\
\hline Length of drive pipe ( $\mathrm{ft}$ ) & 50 \\
\hline \multicolumn{2}{|l|}{ Bit size } \\
\hline Bit Size (production) & 7.875 \\
\hline Bit Size (imtermediate Casing) & 10.625 \\
\hline Bit Size (coal) & 14.75 \\
\hline Bit Size (aquifer) & 17.5 \\
\hline Bit Size (drive) & 24 \\
\hline
\end{tabular}

Fig. 10 The output data in the casing design modeling

well production. The sizes of the four other casings can be determined based on the size of the production casing. The outside diameter of the coupling used on production casing is $6.05 \mathrm{in}$. As discussed earlier, the surface subsidence in coal mine area can cause large vertical and horizontal ground displacement. In this case, the horizontal displacement would cause the bending effect on the casings, which will be discussed later. As for other casing's annular space, the Pennsylvania Code requires that all permanent casing be surrounded by a minimum of $25 \mathrm{~mm}$ ( $1 \mathrm{inch}$ ) of grout at the entire length of casing. Therefore according to the cementing tables of Halliburton and design code of wellbores in Pennsylvania, one can determine the sizes of other casings and couplings. After the casing size is determined, the corresponding bit size can be selected using the bit size table in Fig. 6. Figure 8 shows the schematic view of the designed casings.

\section{Selection of casing strength}

During the selection of the grade of casing, the designer should pay attention to its strength to see whether the selected casing can bear the possible maximum stress and tension. In this model, we are looking into four main strengths corresponding to four types of failures. Those strengths are: collapse resistance, pipe body yield strength, joint strength, and internal pressure resistance (burst strength). After the casing size is selected, a series of casing grade and strength can also be examined. Those grade and strength data are put into the model in terms of the charts corresponding to different types of casing. The following is a brief overview of the casing strength calculation and selections.
Fig. 11 A general view of the current casing design

\section{2-D General View of Casing Radius (inch)}

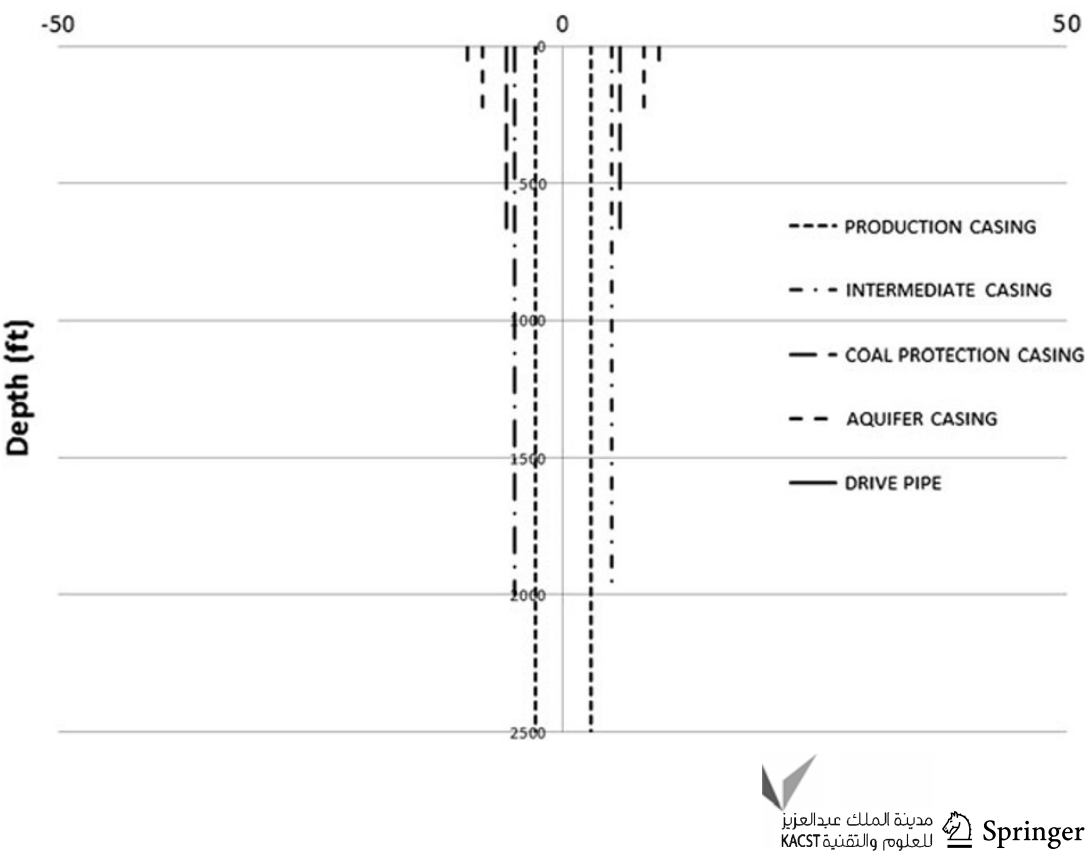




\begin{tabular}{|c|c|c|c|c|c|c|c|c|c|}
\hline Results & Intermediate Casing & OD(inch) & ID(inch) & Density(lbm/ft) & Collapse Resistance(psi) & Grade & Body Yield Strength(lbf) & Joint Stregnth(lbf) & Internal Pressure Resistance(psi) \\
\hline 1 & 1 & 9.625 & 9.001 & 32.3 & 1370 & H-40 & 365000 & 254000 & 2270 \\
\hline 2 & 2 & 9.625 & 8.921 & 38 & 1720 & H-40 & 410000 & 294000 & 2560 \\
\hline 3 & 3 & 9.625 & 8.921 & 36 & 2020 & J-55 & 564000 & 639000 & 3520 \\
\hline 4 & 4 & 9.625 & 8.921 & 36 & 2020 & $k-55$ & 564000 & 755000 & 3520 \\
\hline 5 & 5 & 9.625 & 8.835 & 40 & 2570 & J-55 & 630000 & 714000 & 3950 \\
\hline 6 & 6 & 9.625 & 8.835 & 40 & 2570 & $k-55$ & 630000 & 843000 & 3950 \\
\hline 7 & 7 & 9.625 & 8.835 & 40 & 2990 & C-75 & 859000 & 926000 & 5390 \\
\hline 8 & 8 & 9.625 & 8.835 & 40 & 3090 & L-80 & 916000 & 947000 & 5750 \\
\hline 9 & 9 & 9.625 & 8.835 & 40 & 3090 & N-80 & 916000 & 979000 & 5750 \\
\hline 10 & 10 & 9.625 & 8.835 & 40 & 3250 & C-90 & 1031000 & 1021000 & 6460 \\
\hline 11 & 11 & 9.625 & 8.835 & 40 & 3320 & C-95 & 1088000 & 1074000 & 6820 \\
\hline \multirow[t]{9}{*}{12} & 12 & 9.625 & 8.755 & 43.5 & 3730 & C-75 & 942000 & 1016000 & 5930 \\
\hline & 13 & 9.625 & 8.755 & 43.5 & 3810 & L.80 & 1005000 & 1038000 & 6330 \\
\hline & 14 & 9.625 & 8.755 & 43.5 & 3810 & N-80 & 1005000 & 1074000 & 6330 \\
\hline & 15 & 9.625 & 8.755 & 43.5 & 4010 & C-90 & 1130000 & 1119000 & 7120 \\
\hline & 16 & 9.625 & 8.755 & 43.5 & 4120 & C-95 & 1193000 & 1178000 & 7510 \\
\hline & 17 & 9.625 & 8.755 & 43.5 & 4420 & P-110 & 1381000 & 1388000 & 8700 \\
\hline & 18 & 9.625 & 8.681 & 47 & 4610 & C-75 & 1018000 & 1098000 & 6440 \\
\hline & 19 & 9.625 & 8.681 & 47 & 4760 & L-80 & 1086000 & 1122000 & 6870 \\
\hline & 20 & 9.625 & 8.681 & 47 & 4760 & $N-80$ & 1086000 & 1161000 & 6870 \\
\hline \multirow[t]{9}{*}{13} & 21 & 9.625 & 8.681 & 47 & 5000 & C.90 & 1221000 & 1210000 & 7720 \\
\hline & 22 & 9.625 & 8.681 & 47 & 5090 & C-95 & 1289000 & 1273000 & 8150 \\
\hline & 23 & 9.625 & 8.681 & 47 & 5300 & P-110 & 1493000 & 1500000 & 9160 \\
\hline & 24 & 9.625 & 8.535 & 53.5 & 6350 & C.75 & 1166000 & 1257000 & 7430 \\
\hline & 25 & 9.625 & 8.535 & 53.5 & 6620 & L-80 & 1244000 & 1286000 & 7930 \\
\hline & 26 & 9.625 & 8.535 & 53.5 & 6620 & $\mathrm{~N}-80$ & 1244000 & 1329000 & 7930 \\
\hline & 27 & 9.625 & 8.535 & 53.5 & 7120 & C.90 & 1399000 & 1386000 & 8920 \\
\hline & 28 & 9.625 & 8.535 & 53.5 & 7340 & C.95 & 1477000 & 1458000 & 8460 \\
\hline & 29 & 9.625 & 8.535 & 53.5 & 7950 & P-110 & 1710000 & 1718000 & 9160 \\
\hline
\end{tabular}

Fig. 12 The selection results of the intermediate casing

\section{Collapse design}

For collapse design, it is assumed that the casing is empty inside. The horizontal stress and shear stress in the ground modeling that were discussed previously are taken into account as external loading. To select appropriate casings that can bear the maximum stresses along the well trajectory, one can use safety factor for collapse $\left(N_{c}\right)$ to compare the collapse resistance of casings,

$P_{\mathrm{cc}}=P_{c} * N_{c}$

The estimated horizontal and shear stresses in the ground obtained from numerical modeling are used in the casing design model. If the depth of the groundwater and the coal seam are known, they can be input into the interface of the casing design model. Then the model will compare the stress values from results generated in the numerical model, with depths limited by the depths of the aquifer and the coal seam, and calculate the maximum stresses. This is followed by comparing the maximum stresses to the collapse resistance/strength of the selected casing. If the collapse resistance of the casing is larger than the calculated maximum load on casing, this type of casing will be considered sufficient for well completion.

The collapse design uses the external stress from the formation surrounding the casings, so the ground modeling results have a significant impact on the selection of the casing grade and the estimated casing stresses. If the ground deformation in the mining area leads to considerable horizontal stress or shear stress acting on the casings, the casings may experience the risk of collapse failure. Therefore, the reliability of the ground modeling results needs to be taken into consideration.

\section{Burst design}

For burst design, it is assumed that there is no "backup" fluid outside the casing. The mud density, pore pressure gradient, and fracture gradient data are provided by the designer and used in the calculation of injection pressure (Fig. 9). For burst consideration, it is assumed that any gas kick is composed of methane with molecular weight of 16 and ideal gas behavior. The formation temperature is equal to $520+0.012 \mathrm{H}$, where $H$ is the depth of the casing. To obtain the maximum burst pressure along the well trajectory, the injection pressure $\left(p_{i}\right)$ is needed,

$p_{i}=0.052 * \rho_{m} * H$

We can then calculate the gas gradient for the calculation of casing internal pressure. Here, the real gas equation is introduced:

$\rho_{g}=\frac{p M}{z R T}($ in consistent units $)=\frac{p M}{80.3 z T}($ in field units $)$

Since the gas gradient $=0.052 \rho_{g}$, the casing internal pressure $P_{\text {in }}$ (psig) will be 
$P_{\text {in }}=p_{i}-0.052 \rho_{g} H$,

Then the safety factor for burst $\left(N_{i}\right)$ is used to compare the internal pressure resistance of casings with the burst design load as

$P_{i}=P_{\text {in }} * N_{i}$

If the estimated internal pressure resistance of casing is larger than the calculated maximum internal pressure inside the casing, this type of casing selected is considered to be sufficient.

As for the burst design, the depth of casing can influence the internal pressure significantly. Since the mud density is essentially constant during calculation of the injection pressure, the internal pressure tends to be a function of depth. Increased internal pressure requires casing with a higher internal pressure resistance. Thus, more attention should therefore be paid to the depth of casing.

\section{Tension design}

For tension design, both the body yield strength and the coupling strength of casing are taken into consideration. From the casing design data, which are input parameters for the spreadsheet, the model can use the density of each casing to calculate the axial tension on the body of the casing for various depths of casing. As discussed in previous sections, the bending effect is also considered in this part of the model. In this model, we assumed that the maximum horizontal displacement can be $100 \mathrm{~mm}$ (four inches), which causes a curvature on the well and an increase on the axial tension. To quantify the axial force caused by bending effect, the following equation can be utilized:

$F_{\mathrm{ab}}=64 \alpha d_{n} w$,

If both the body yield strength and the coupling strength exceed the maximal axial tension, the casing selected can be an option. The minimum tensile yield strength and the minimum joint strength would then be

$F_{a}=\left(W+F_{\mathrm{ab}}\right) * N_{a}$,

$F_{j}=\left(W+F_{\mathrm{ab}}\right) * N_{j}$.

In the case of tension, the pipe body weight is not a factor that could lead to failure. The casing length is not significantly long, so that the pipe body weight does not cause a tremendous axial load. However, the load caused by bending effect needs to be thoroughly analyzed and considered in the selection of the proper casing. Since there is a horizontal displacement around the surface, which could result in casing deformation, all the casings may produce an extra axial load that is generated by bending. So this issue was considered along with the pipe body weight in tension design to prevent the casing from being damaged by unexpected axial loads.

All the casings are selected by checking the three performance properties as noted above to assure that they meet the regulatory and design requirements. The user will provide the input parameters including depth of the coal seam and the fresh groundwater and the model will generate the results including a schematic view of the casings, the outside and inside diameter of the aquifer casing, the grade and type of aquifer casing, coal protection casing, and drive pipe.

\section{Casing design model result}

In this study, safety factors used for estimation of the stresses and forces acting on the casings are $N_{a}=N_{j}=1.8$, $N_{c}=1.125$, and $N_{i}=1.1$. The coal seam depth was fixed to a depth of $200 \mathrm{~m}$ (660-670 ft). The depth of groundwater can be variable between 60 and $120 \mathrm{~m}(200-400 \mathrm{ft})$. Since the ID (5.5 in) and OD (6.05 in) for the production casing is already determined, the results start with the ID of coal protection casing and proceeds to select other casings and related bit sizes. Figure 10 shows the size of all the casings and bits as the outputs for an example case. The ID and OD of the coal protection casing, intermediate casing, aquifer casing, and drive pipe are listed. All the casing lengths are applied to the same assigned sections. After the results of modeling for size and length of casings were obtained, a general view of casing combination was generated in the model, as shown in Fig. 11. To control the

Table 2 The design result of casing depths, casing sizes, and casing bit sizes

\begin{tabular}{ll}
\hline Item & Modeling result \\
\hline Drive pipe depth (ft) & 50 \\
Dive pipe diam. OD/ID (in) & $20^{\prime \prime} / 19^{\prime \prime}$ \\
Drive pipe bit size (in) & $24^{\prime \prime}$ \\
Aquifer casing depth (ft) & Aquifer depth +50 \\
Aquifer casing diam. OD/ID (in) & $16^{\prime \prime} / 15.01^{\prime \prime}$ \\
Aquifer casing bit size (in) & $171^{\prime \prime}$ \\
Coal protective casing depth (ft) & Coal Seam depth +40 \\
Coal protective casing diam. OD/ID (in) & $11^{3} / 4^{\prime \prime} / 10.772^{\prime \prime}$ \\
Coal protective casing bit size (in) & $14^{3} / 4^{\prime \prime}$ \\
Intermediate casing depth (ft) & 2000 \\
Intermediate casing diam. OD/ID (ft) & $95 / 8^{\prime \prime} / 8.679^{\prime \prime}$ \\
Intermediate casing bit size (ft) & $10^{5} / 8^{\prime \prime}$ \\
Production casing depth (ft) & As Needed \\
Production casing diam. OD/ID (in) & $6^{\prime \prime} / 5^{1} / 2^{\prime \prime}$ \\
Production casing bit size (in) & $77 / 8$ \\
\hline
\end{tabular}




\begin{tabular}{|c|c|c|c|c|c|c|c|c|c|}
\hline Results & Coal Protection Casing & $O D$ (inch) & ID(inch) & Density(lbm/ft) & Collapse Resistance(psi) & Grade & Body Yield Strength(lbf) & Joint Stregnth(lbf) & Internal Pressure Resistance(psi) \\
\hline 1 & 1 & 11.75 & 10.772 & 60 & 2660 & J.55 & 952000 & 1042000 & 4010 \\
\hline 2 & 2 & 11.75 & 10.772 & 60 & 2660 & $k-55$ & 952000 & 1208000 & 4010 \\
\hline 3 & 3 & 11.75 & 10.772 & 60 & 3070 & $c-75$ & 1298000 & 1361000 & 5460 \\
\hline 4 & 4 & 11.75 & 10.772 & 60 & 3180 & L.80 & 1384000 & 1399000 & 5830 \\
\hline 5 & 5 & 11.75 & 10.772 & 60 & 3180 & $N-80$ & 1384000 & 1440000 & 5830 \\
\hline 6 & 6 & 11.75 & 10.772 & 60 & 3360 & C.90 & 1557000 & 1517000 & 6300 \\
\hline 7 & 7 & 11.75 & 10.772 & 60 & 3440 & C-95 & 1644000 & 1596000 & 6300 \\
\hline \multirow[t]{6}{*}{8} & 8 & 11.75 & 10.772 & 60 & 3610 & P-110 & 1903000 & 1877000 & 6300 \\
\hline & 9 & 11.75 & 11.084 & 42 & 1040 & $\mathrm{H}-40$ & 478000 & 307000 & 1980 \\
\hline & 10 & 11.75 & 11.000 & 47 & 1510 & J-55 & 737000 & 807000 & 3070 \\
\hline & 11 & 11.75 & 11.000 & 47 & 1510 & K-55 & 737000 & 935000 & 3070 \\
\hline & 12 & 11.75 & 10.880 & 54 & 2070 & J-55 & 850000 & 931000 & 3560 \\
\hline & 13 & 11.75 & 10.880 & 54 & 2070 & K-55 & 850000 & 1079000 & 3560 \\
\hline
\end{tabular}

Fig. 13 The selection results of the coal protection casing

\begin{tabular}{|c|c|c|c|c|c|c|c|c|c|}
\hline Results & Aquifer Casing & $\mathrm{OD}$ (inch) & ID(inch) & Density(lbm/ft) & Collapse Resistance(psi) & Grade & Body Yield Strength(lbf) & Joint Stregnth(lbf) & Internal Pressure Resistance(psi) \\
\hline 1 & 1 & 16 & $\overline{15.010}$ & 84 & 1410 & $J-55$ & 1326000 & 1351000 & 2980 \\
\hline 2 & 2 & 16 & 15.010 & 84 & 1410 & $k-55$ & 1326000 & 1499000 & 2980 \\
\hline 3 & 3 & 16 & 15.124 & 75 & 1020 & J-55 & 1178000 & 1200000 & 2630 \\
\hline 4 & 4 & 16 & 15.124 & 75 & 1020 & K-55 & 1178000 & 1331000 & 2630 \\
\hline & 5 & 16 & 15.250 & 65 & 630 & H. 40 & 736000 & 439000 & 1640 \\
\hline
\end{tabular}

Fig. 14 The selection results of the aquifer casing

\begin{tabular}{|c|c|c|c|c|c|c|c|c|c|}
\hline Results & Drive Pipe & OD(inch) & ID(inch) & Density(lbm/ft) & Collapse Resistance(psi) & Grade & Body Yield Strength(lbf) & Joint Stregnth(lbf) & Internal Pressure Resistance(psi) \\
\hline & 1 & 20 & 19.000 & 106.5 & 770 & J.55 & 1685000 & 1596000 & 2320 \\
\hline & 2 & 20 & 19.000 & 106.5 & 770 & K-55 & 1685000 & 1683000 & 2320 \\
\hline 3 & 3 & 20 & 18.730 & 133 & 1500 & J-55 & 2125000 & 2012000 & 2320 \\
\hline \multirow[t]{4}{*}{4} & 4 & 20 & 18.730 & 133 & 1490 & K-55 & 2125000 & 2123000 & 2320 \\
\hline & 5 & 20 & 19.124 & 94 & 520 & H-40 & 1077000 & 581000 & 1530 \\
\hline & 6 & 20 & 19.124 & 94 & 520 & J-55 & 1480000 & 1402000 & 2110 \\
\hline & 7 & 20 & 19.124 & 94 & 520 & K-55 & 1480000 & 1479000 & 2110 \\
\hline
\end{tabular}

Fig. 15 The selection results of the drive pipe

casing strength design, the results of shear stress and horizontal stress along the wellbore were obtained from the ground modeling, as shown in Fig. 10. The continuation of the design process involves selection of the casings that satisfy all the performance and strength criteria and the casing minimum performance properties (Table 2). The result of the selection process is illustrated in Figs. 12, 13, 14 , and 15.

\section{Conclusions}

In situ stress and induced stress in longwall mining areas are analyzed to examine the possibility of damages to the wellbore casing. Numerical modeling of the ground was carried out to better estimate and quantify the stresses, strains, and resulting deformation in the ground to determine the stress distribution in the ground and along the well trajectory within a pillar in the layout of a longwall mining area. For this analysis, the gas wells are assumed to be placed in the middle of the abutment pillars in the head/tail gate in a three entry development system, which is typical of longwall mining operations in southwest Pennsylvania. A parametric study was performed using the pertinent parameters to study the impact of variation on rock properties and panel geometric parameters on the stresses and strains due to mining. This includes Young's modulus, Poisson's ratio, unit weight, and element length, as well as depth and pillar sizes. The results of the parametric study show that the variations in these parameters within a limited range do not change the estimated strain and deformation values drastically and the outcome of the numerical analysis is valid over a reasonable range for these parameters. The highest sensitivity of the numerical modeling seems to be relative to unit weight of the overburden rock.

We then quantified the effect of induced stresses and strains in the strata above coal caused by the mining activities on casing in the longwall mining areas and possibility of wellbore failure. The calculated stresses and strains were in turn used in a model to offer a safe casing design based on the depth to the aquifer and coal seam. The model is capable of offering the casing design by incorporating guidelines by API and regulations by Pennsylvania Department of Environmental Protection. 
Other conclusions are summarized as follows.

- The critical location for casing failure is near surface, where the magnitude of maximum horizontal displacement seems to be the highest. Also in the interval along the casings around the coal seam, where largest stresses have been observed there is a possibility of wellbore failure.

- The maximum horizontal displacement is extremely large, close to the ground surface. High values of displacement have been estimated in the modeling, which has been observed in Australia where a peculiar surface topography exists.

- A five string casing program is recommended for use in these conditions. The five string casing system will include the drive pipe, aquifer casing, coal protection casing, intermediate casing, and production casing. This casing program has been widely used in Marcellus gas well completions in PA and surrounding areas where the well clusters happen to be near coal mines using the longwall mining method. A model has been developed for casing design by including the stress and strain results from our numerical analysis of ground in the longwall mining areas. Our model helps select casing lengths, casing sizes, and bit sizes.

- The casing design from our model would be optimal given that coal interval is from 656 to $662.5 \mathrm{ft}$, regardless of aquifer depth, types and depth of intermediate casing, or types and depth of production casing. If coal seam does not fit the assumption, ground modeling needs to be conducted to quantify horizontal displacement and stresses change which are then used as inputs in the casing design model for optimized casing design.

- The methodology may be applied to investigate casing stability and help optimize well completions in areas that experience subsidence from longwall mining of coal.

Open Access This article is distributed under the terms of the Creative Commons Attribution License which permits any use, distribution, and reproduction in any medium, provided the original author(s) and the source are credited.

\section{References}

Bourgoyne AT, Chenevert ME, Millhein KK (1986) Applied drilling engineering. Textbook Series, SPE, Richardson, pp 246-348

Gutierrez JJ, Vallejo et al. (2010) Impact of longwall mining on highways. Paper ARMA 10-151 presented at the 44th US Rock Mechanics Symposium and 5th US-Canada Rock Mechanics Symposium, Salt Lake City

Peng (2008) Coal mine ground control. Department of Mining Engineering, West Virginia University, USA

Rostami J, Elsworth D, Watson R (2012) Study of borehole stability for gas wells in longwall mining areas. Pennsylvania State University, State College, Pennsylvania 